\title{
Construction of an Integrated Social Vulnerability Index to Identify Spatial Variability of Exposure to Seismic Hazard in Pahang, Malaysia
}

\author{
Noor Suhaiza Sauti ${ }^{1,2 *}$, Mohd Effendi Daud ${ }^{1}$, Masiri Kaamin ${ }^{3}$ \\ ${ }^{1}$ Faculty of Civil Engineering and Built Environment, University Tun Hussein Onn Malaysia, Parit Raja 86400, Batu Pahat, \\ Johor, Malaysia \\ ${ }^{2}$ Department of Polytechnic \& Community College Education, Ministry of Education Malaysia, Putrajaya 62100, Malaysia \\ ${ }^{3}$ Centre for Diploma Studies, University Tun Hussein Onn Malaysia, Parit Raja 86400, Batu Pahat Johor, Malaysia
}

Corresponding Author Email: gf180003@ siswa.uthm.edu.my

https://doi.org/10.18280/ijdne.150310

Received: 5 February 2020

Accepted: 15 April 2020

\section{Keywords:}

GIS, index, multivariate analysis, Pahang, seismic hazard, social vulnerability

\begin{abstract}
Devastating effects of natural disasters dynamically depends on the vulnerability components of a specific area. Therefore, assessing vulnerability is necessary to estimate the earthquake risk. This paper argues for a multidisciplinary method that integrates social vulnerability into the seismic risk analysis in Pahang. The methodology specifically relies on; (1) the development on a set of social indicators using multivariate data analysis to identify and evaluate the local characteristics that contribute to the vulnerability and risk of inhabitants of district space; and (2) the application of Geographical Information System (GIS) technology for generating and mapping the spatial pattern of social vulnerability index for seismic hazard in Pahang, Malaysia that was based on the classification of its exposure level. The classes of a social vulnerability index map were overlaid with a seismic hazard map that was proposed by JMG (Mineral and Geoscience Department Malaysia) through the use of map algebra functions in GIS tools. Results for social vulnerability map showed that, majority of the study area are in relatively low to moderate level except for Kuantan district, which is highly vulnerable. Meanwhile, the combination of the social vulnerability map and seismic hazard map reveals that, districts in the central parts of the region are the most highly exposed to earthquake threats, whereas in the eastern part it demonstrates the low level of exposure to seismic hazard (with the exception for the Kuantan district, where it is highly vulnerable). The proposed method provides useful information on the spatial variability of exposure vulnerability to seismic hazard that could enhance the earthquake preparedness and mitigation.
\end{abstract}

\section{INTRODUCTION}

Various vulnerability definitions have been suggested by organizations [1, 2] and authors [3-5], but generally, vulnerabilities could be defined as the reduction of the capacity of a person or a community to anticipate, deal with, resist and recover from the impact of disasters. The key term for understanding the definition of disaster and risk could described because of the relationship between hazard and vulnerability [6]. The nature and the extent of absolute risk related to the potential hazard and the existing circumstances of vulnerability that encompasses the characteristics and conditions of a community, system, or properties from the effects of a hazard [7-9]. In counteracting the vulnerability factor, it would require the recognition of multi-dimensional factors that are related to social, cultural, physical, environmental, and human elements that are continuously changing over time and space [10].

The concept of social vulnerability highlights the potential impact of disaster on groups that are associated with demographic, socio-economic, cultural, and physical aspect, such as age structure, gender, disability, household, education level, poverty, gross income, density of built structure and others $[5,11,12]$. The combination of these factors might increases or decreases the potential risk due to the effects of natural disasters on the population. In order to measure the social vulnerability and spatial variability of population to disasters, qualitative and quantitative methods have been introduced. Cutter et al., [5] had developed the Social Vulnerability Index (SoVI) containing location-based indicators to measure and identify the major factors influencing social vulnerability. The SoVI framework has been adapted and applied in several locations and social environments in order to better understand the factors impacting the vulnerability of the population [10, 11, 13-15].

It is a known fact that the implementation of earthquake disaster management in Malaysia is still in its early-stage, [16] hence, there is a dearth of quantitative assessment of social vulnerability to earthquakes in Malaysia due to the lack of social data for analysis and mapping. Thus, this research proposes a model that integrates the social vulnerability index in evaluating the exposure of population and properties to seismic hazard in Pahang, Malaysia. Accordingly, the multivariate data analysis technique is applied to produce the composite index of social vulnerability and using GIS platform in identifying and classifying the exposure vulnerability of study area to seismic threat. The spatial distribution of the social vulnerability indicators provides a basis for risk-reduction policies [5].

The result of this research is the social vulnerability map 
that has been derived from the integrated social vulnerability index framework and the exposure map by combining the social vulnerability map with seismic hazard map of Pahang region. The level of exposure and vulnerability of the population and residential aspects against earthquake are highly influenced by the disaster impact [17]. Thus, the assessment of exposure level for Pahang is essential in providing preliminary information on disaster mitigation and strategies.

\section{DATA COLLECTION AND METHODOLOGY}

\subsection{Study area and data collection}

The study area is the Pahang state, located on Peninsula Malaysia at the latitude of $3^{\circ} 58^{\prime} 27.6276^{\prime \prime} \mathrm{N}$ and longitude of $102^{\circ} 26^{\prime} 17.0052^{\prime \prime}$ E. Pahang known as the largest Peninsula Malaysia state which covers an administrative area of 35,965 $\mathrm{km}^{2}$ with approximately 1.6 million populations. Most of the northern suburbs are surrounded by hilly and mountainous areas (Figure 1).

In terms of its seismic profile, Pahang is relatively low with stable geological condition. However, between 2007 and 2010, not less than 24 minor local earthquakes with magnitudes ranging from 1.7 to 3.5 had occurred in the Bentong Fault
Zone (Bukit Tinggi Fault and Kuala Lumpur Fault) [18]. This is assumed to be the result of the reactivation of ancient dormant fault due to stress from the built-up source of neighbouring seismic events in Sumatra, Indonesia [19]. Therefore, the region requires particular attention from the responsible agencies in identifying the level of seismic exposure to occupants and residential properties as initial information on disaster preparedness and mitigation.

In order to achieve the aim of this study, the data is collected and structured on the basis of the need to define and create measures of vulnerability to exposure at the district level. Readily available data from various federal government agencies are gathered and organized according to the module application in the database. The agencies involved are the Malaysian Centre for Geospatial Data Infrastructure (MacGDI), Malaysian Meteorological Department (MET Malaysia), Mineral and Geoscience Department Malaysia (JMG) and Department of Statistics Malaysia (DOSM). The data used to create the Pahang Social Vulnerability Index were mainly taken from the 2010 Census record obtained from DOSM. The list of data layer, format, and sources are arranged as shown in Table 1. The data is the most crucial component in defining the success of GIS application. Therefore the required data for this study are identified according to the data types either spatial or attribute data and data format (vector or raster).

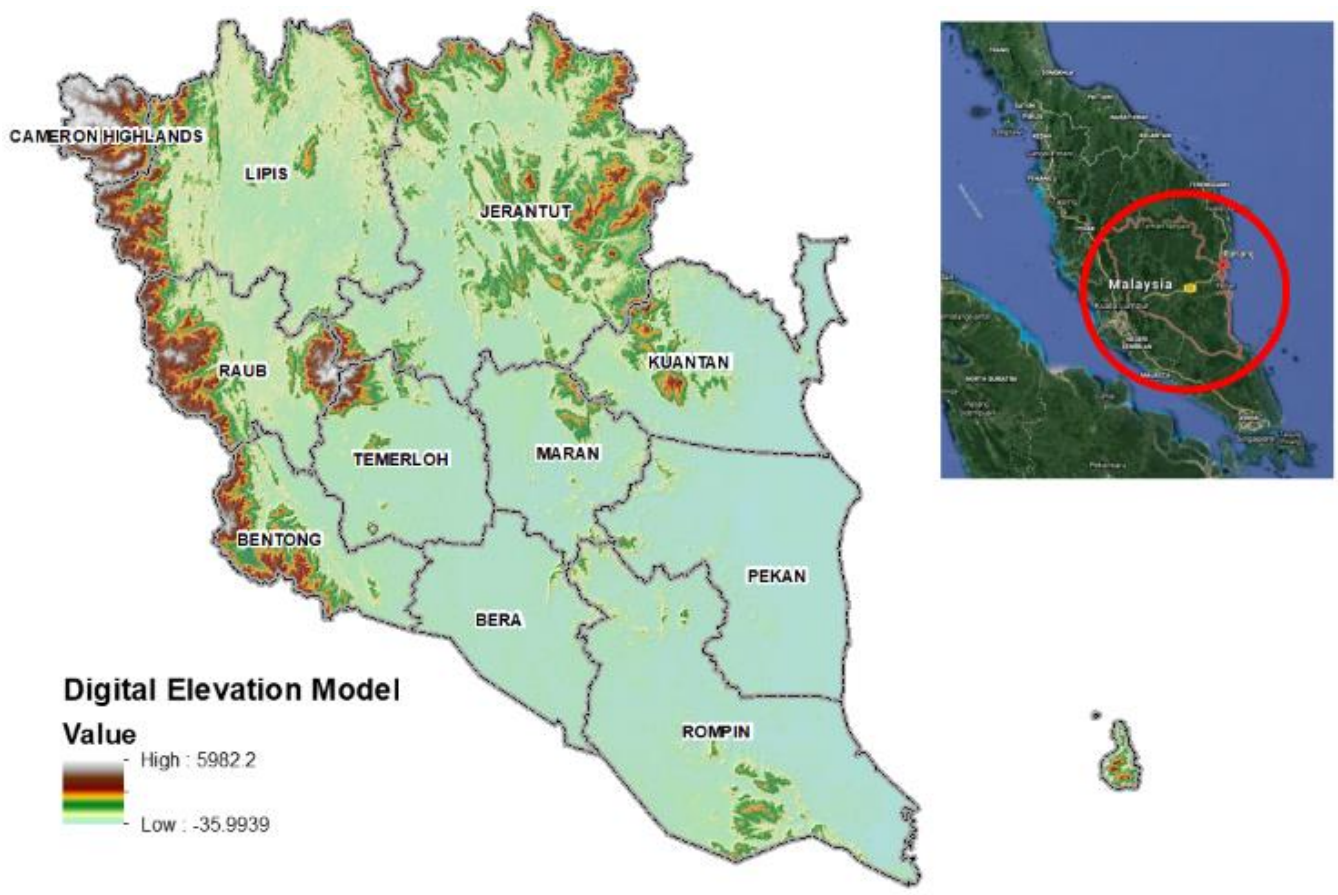

Figure 1. Study area

Table 1. List and details of data and sources

\begin{tabular}{ccccc}
\hline No & Module & Data layer & Format & Source \\
\hline 1 & Hazard layer & Fault & Line- vector & JMG \\
& & Seismic zone & Polygon- vector & JMG \\
\hline 2 & Cadastral layer & State map & Polygon- vector & MacGDI \\
& & Country & Polygon-vector & MacGDI \\
& & District & Polygon-vector & MacGDI \\
& & Line - vector & MacGDI \\
& & Administration boundary & Raster image & MacGDI \\
\hline 3 & Exposure layer & Buill shade (DEM) & Polygon- vector & MacGDI \\
& & Population / Census & Polygon-vector and attribute data (excel format) & DOSM \\
\hline
\end{tabular}




\subsection{Assessing social vulnerability to seismic hazard}

This study conducted is based on quantitative and qualitative vulnerability assessment and index construction at a district scale. It integrates GIS-based modeling along with a spatial multivariate data analysis of social vulnerability indicators. Figure 2 illustrates the methodological framework guiding the analytical procedure.

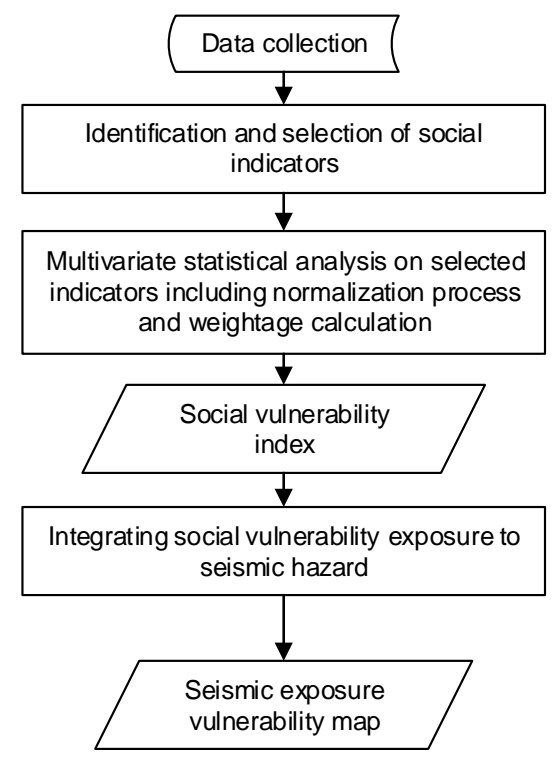

Figure 2. The methodological framework for assessing social vulnerability index to seismic hazard

The methodological flowchart of research design comprises of main procedures with the goal of constructing an integrated social vulnerability index and identifying the spatial variability of exposure to seismic hazard.

\subsubsection{Indicators for social vulnerability indices}

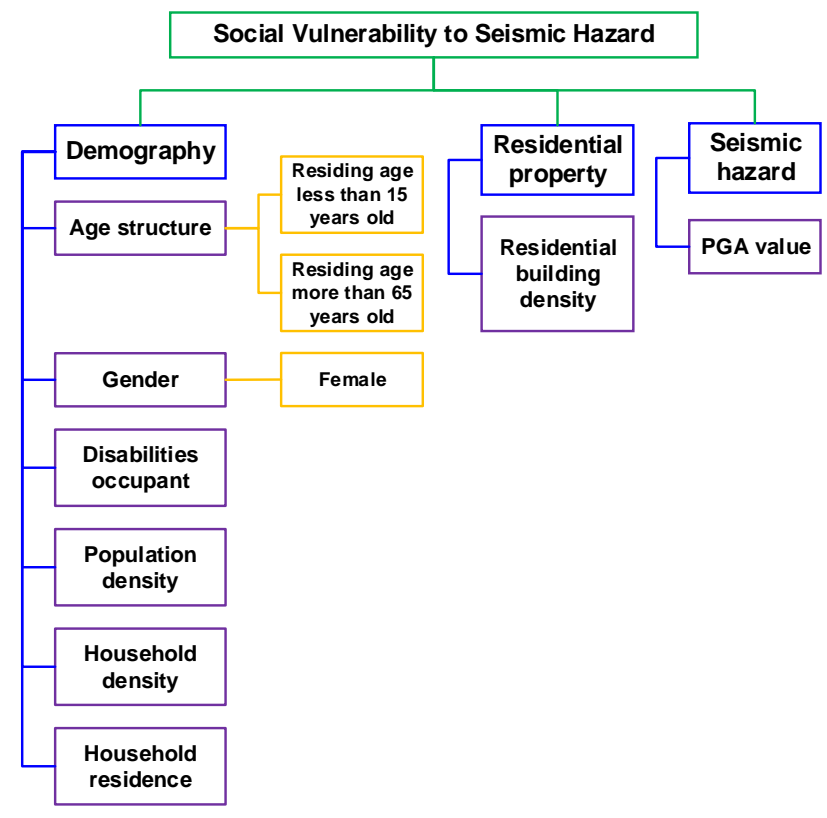

Figure 3. Structure of the social vulnerability indices

Indicators are measurable variables meant to be descriptive of a system of interest. There are no set rules for the construction of the social vulnerability index [20]. The differences in the set of variables of potential variables for the social vulnerability index are significantly influenced by previous studies, the availability of related data, and the expert opinion. Social vulnerability is frequently defined by the following specific characteristics of people; age, gender, health, income, types of dwelling unit, employment and many more $[5,11]$. Normally, these social factors do affect or shape the level of vulnerability and resilience of diverse groups of people and impact their capacity to react to disaster. The indicators for social vulnerability indices in this study is designed and structured as shown in Figure 3.

Demography. Demographic data consists of important statistical information in assessing the vulnerability of people and property during disasters. Therefore, demographic data from census data are a good source of information on a variety of aspects that are especially important for constructing social vulnerability indices. Indicators of social vulnerability to disasters are related to age structure, gender, disability status, household criteria, and other significant relationships.

Population of children (age less than 15 years old) are identified as the most affected group, as they are unable to produce proper response activity during disasters because of their lack of the tools, expertise or life experience needed to deal effectively with the situation $[5,15,21]$. In addition, affected childcare facilities require more time and financial aspects to properly care for children $[11,13,22]$. Similarly, elderly people over 65 years of age are more likely to have mobility issues or mobility limitations that often raised the burden of care and lack of resilience. Many elderly people need special services and help from others, especially in the event of a disaster. Elders living alone are typically to be relied on, and may be more likely to be vulnerable to disaster $[5,13$, $21,22]$.

Gender affects vulnerability, where women can have a more difficult time of recovery than men, mainly due to sectorspecific employment, lower income, and family care responsibilities $[5,12,15,21]$. Similarly, disabled people of all ages with physical, sensory, or cognitive disorders are known to be at greater risk of experiencing adverse effects from natural disasters $[11,23]$.

Population density is represented by the population distribution expressed as the absolute number of people per unit mapping. High population density could increase the potential for damage to areas and conditions exposed to natural disasters. Rapid growth in high-density areas would lead to low quality housing, and the social services network would not align with the process of adaptation to growing populations $[11,24]$. Problems with the communication and assimilation of local cultures among new migrants would result in poor delivery of disaster relief information, or disaster recovery process that would increase their vulnerability [13, 21, 22, 25].

Household variables is applied to the family structure, for single-parent households and large households are categorized as potentially vulnerable when combined with unstable socioeconomic circumstances that prohibit them from generating adequate income to support their dependencies [5, 12].

Residential property. Vulnerable buildings are a significant factor that could cause damages and destruction of property in the event of an earthquake. Collapsed walls or large objects falling from buildings would cause many people to be injured or killed in the event of earthquakes. The density of buildings, specifically residential buildings, is determined by the number 
of physical buildings relative to the number of areas most likely to be affected by the earthquake $[21,26]$. As a result, areas with high density of residential buildings have higher rates of risk and vice versa.

Seismic hazard. Seismic hazards refer to hazards associated with the possibility of earthquake in a geographical region, where the seismic hazard map indicates the relative hazards in a specific area [27]. One of the crucial components in generating a seismic hazard map is the distribution of maximum peak ground acceleration (PGA) within a return period. PGA is a measurement of earthquake intensity in measuring the severity of earthquake damage related to the basis of calculation applications in construction fields such as the assessment of earthquake-resistant structure, building code, seismic hazard risk and more. Therefore, the PGA value is closely related to the Modified Mercalli Intensity (MMI) intensity scale in measuring earthquake damage potential.

Seismic hazard maps provide valuable information on the seismic hazard zone to help authorities identify the level of earthquake threat and assist in the development and planning of disaster response. The classification of seismic hazard zone for the study area is based on Table 2 [28] and shown together with faults distribution in Figure 4. The Bentong district in the central-west part of Pahang lay within the hazardous seismic zone, which encompasses the Bukit Tinggi Fault. The majority of the areas that are at lower risk of earthquake hazard are situated either in Zone II or Zone III of the region.

Table 2. Comparison of Richter scale magnitude with Modified Mercalli Intensity (MMI) scale

\begin{tabular}{cc}
\hline Magnitude & Maximum Modified Mercalli Intensity \\
\hline $1.0-3.0$ & I \\
$3.0-3.9$ & II - III \\
$4.0-4.9$ & IV - V \\
$5.0-5.9$ & VI - VII \\
$6.0-6.9$ & VII - IX \\
$>7.0$ & VIII and above \\
\hline
\end{tabular}

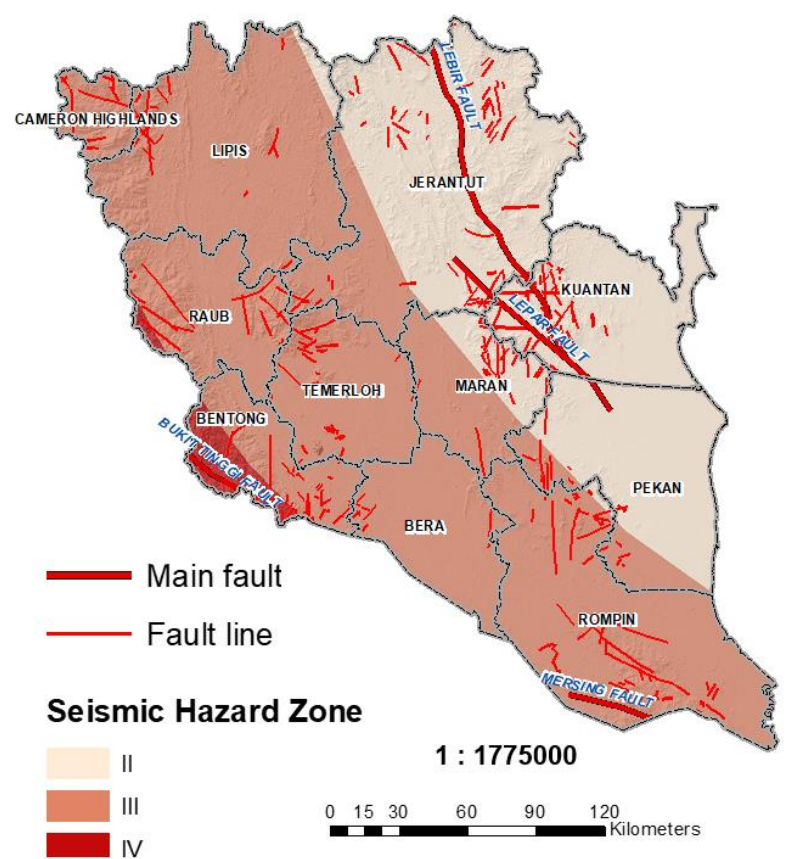

Figure 4. Seismic hazard zone and faults distribution in Pahang
2.2.2 Multivariate data analysis to social indicators

Various techniques have been used to determine the vulnerability index of areas to earthquake [29-32]. This research has been carried out in accordance to Iyengar and Sudarshan's approach, which essentially is a multivariate data analysis method in normalizing and calculating the weighting for selected indicators excluding the seismic hazard component. The standardization of the multi-source data was performed through the following normalization Eq. (1) [33, 34]. The normalized values fall between 0 and 1 [35].

$$
N_{i j}=\frac{N_{i j}-\operatorname{Min}\left(N_{i j}\right)}{\operatorname{Max}\left(N_{i j}\right)-\operatorname{Min}\left(N_{i j}\right)},\left(0 \leq N_{i j} \leq 1\right)
$$

$N_{i j}$ is the normalized value that is dimensionless. Then, it is used to calculate the linear sum of $N_{i j}$ using following Eq. (2) where $K$ is the indicator of vulnerability with $\mathrm{M}$ represents the region or district. $w_{j}$, weight of indicator variable $(0<w$ $<1$ ) and $\sum_{i=1}^{K} w_{j}=1$. Eqns. (3) and (4) compute the weight $\left(w_{j}\right)$ values for each different indicator variables with $\mathrm{c}$ representing the normal constant.

$$
\begin{gathered}
\bar{y}_{i}=\sum_{j=1}^{K} w_{j} N_{i j} \\
w_{j}=c / \sqrt{\operatorname{var}\left(x_{i j}\right)} \\
\left.c=\mid \sum_{i=1}^{j=K} 1 / \sqrt{\operatorname{var}\left(x_{i j}\right)}\right]^{-1}
\end{gathered}
$$

Getting an appropriate weight for each indicator is an important aspect of the vulnerability evaluation, as indicators have a specific degree of contribution for vulnerability. The estimated weight for the social indicator is shown in the following Table 3 .

Table 3. List social indicator variables and calculated weight

\begin{tabular}{cc}
\hline Variable indicator & Weight \\
\hline Age structure (less than 15 years old) & 0.1342 \\
Age structure (more than 65 years old) & 0.1391 \\
Gender (female occupant) & 0.1332 \\
Disabilities occupant & 0.1295 \\
Population density & 0.1272 \\
Household density & 0.1232 \\
Household residence density & 0.1224 \\
Residential building density & 0.0912 \\
\hline
\end{tabular}

2.2.3 Social vulnerability index map generation and exposure to seismic hazard

The index values obtained from the multivariate analysis are used in mapping and identifying vulnerable areas using GIS tools. The weighted layers are overlaid to produce social vulnerability map using weighted sum function (Figure 5).

The derived maps were then classified based on the pixel values using the standard deviation method into four different categories of vulnerability level; Low, Moderate, High, and Very High (Figure 7) [10, 13, 22]. The final process would involve the integration of the social vulnerability index map to identify the exposure of study area towards the seismic hazard. The raster calculator tool is applied to calculate the the geometric intersection of social vulnerability map in conjunction with the seismic hazard map. The overall process is shown in Figure 6. 


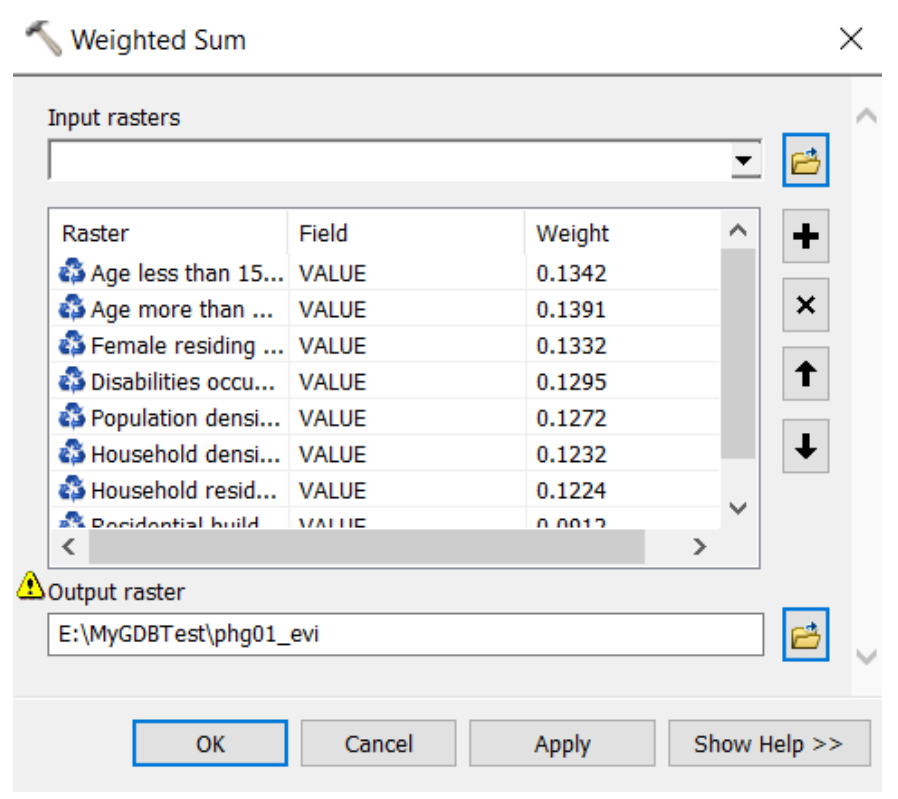

Figure 5. Weighted sum function to overlay the social indicator layers

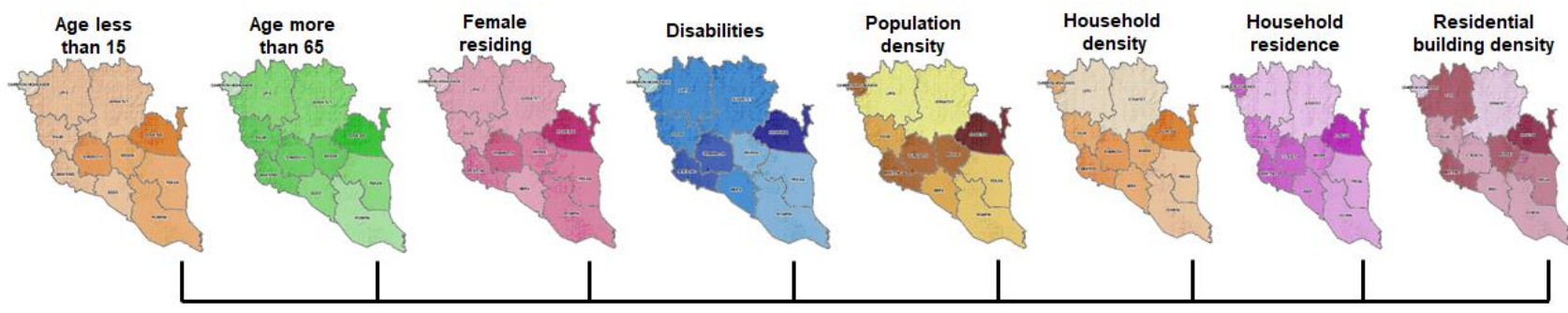

Combining all social indicators using Weighted Sum function

Social vulnerability index map

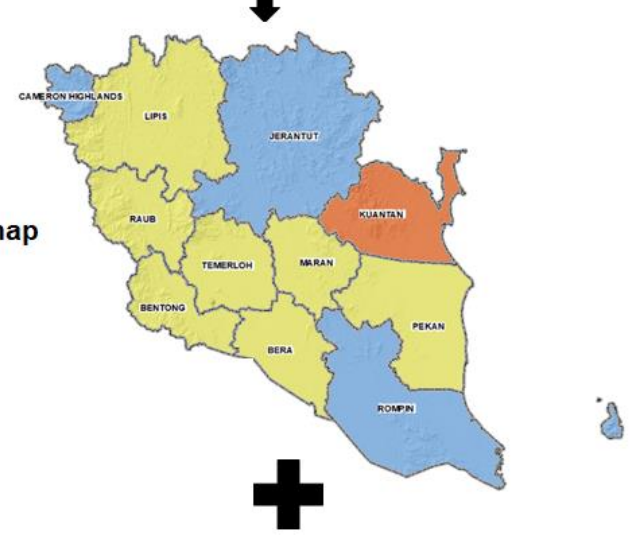

Overlay layers using Raster Calculator tool

Seismic hazard map

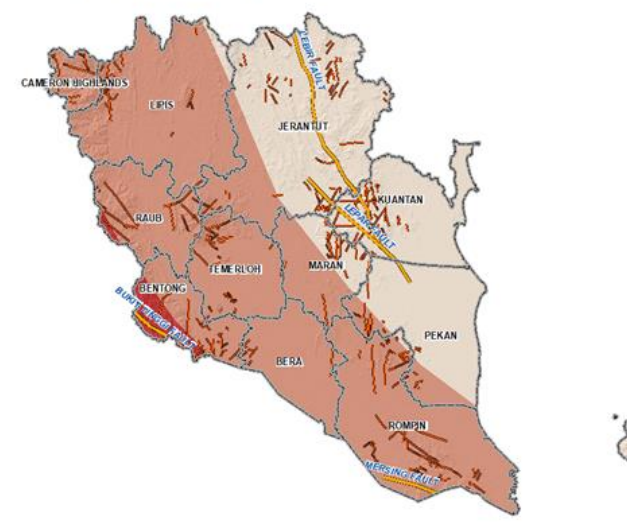

Figure 6. The process to produce social vulnerability exposure map 


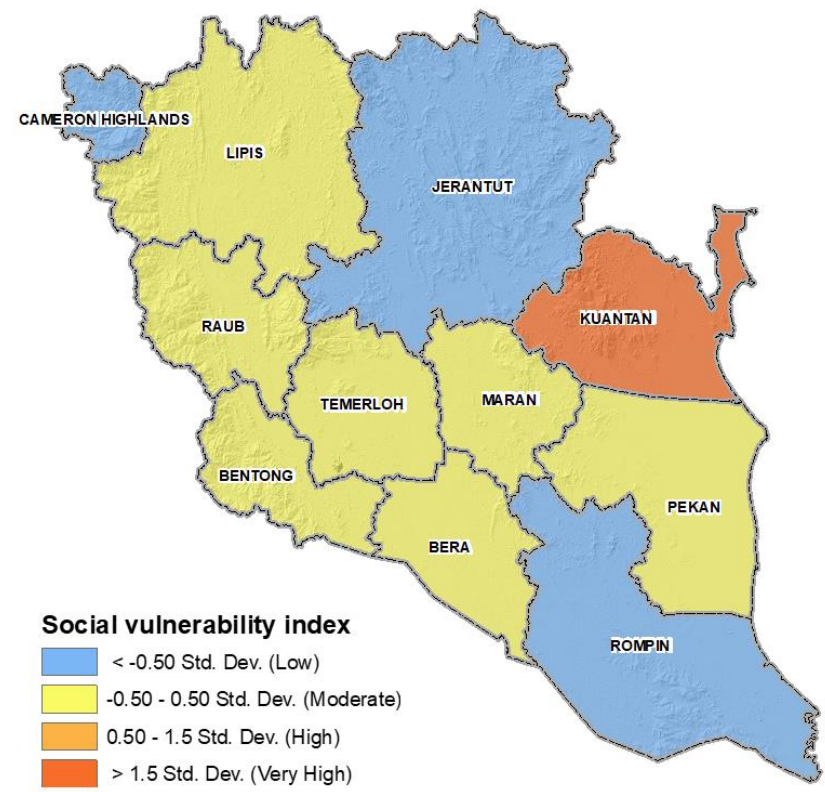

Figure 7. Social vulnerability index map for Pahang

\section{RESULTS AND DISSCUSIONS}

The social vulnerability maps that is produced from multivariate data and GIS tools have displayed different classes of vulnerability against natural disasters, ranging from low vulnerable areas to high vulnerability. Based on Figure 6, majority or more than $90 \%$ of the districts in Pahang show relatively low to moderate level of social vulnerability index with small mean value (0.036) and standard deviation (0.031) (Figure 8). Only Kuantan district shows the highest social vulnerability index with Std Dev more than 1.5 that represent $9 \%$ of the study area. The Kuantan district recorded higher values as compared to other districts with regards to influencing factors including the number of vulnerable populations exposed to earthquake in terms of number of children, the elderly, women, the disabled residing, and residential building density.

Conversely, several districts display the low level of social vulnerability index with its Std Dev smaller than -0.5 , which refers to Cameron Highlands, Jerantut, and Rompin. The classification information on the social vulnerability index is presented in Table 4.

Table 4. Classification information on social vulnerability index

\begin{tabular}{cccc}
\hline District & Classification & $\begin{array}{c}\text { Social } \\
\text { Vulnerability } \\
\text { Index }\end{array}$ & $\begin{array}{c}\text { Std. Dev } \\
\text { range }\end{array}$ \\
\hline Kuantan & Very High & 0.1250 & $>1.5$ \\
Bentong & Moderate & 0.0478 & $-0.5-0.50$ \\
Maran & Moderate & 0.0394 & $-0.5-0.50$ \\
Pekan & Moderate & 0.0226 & $-0.5-0.50$ \\
Rompin & Moderate & 0.0160 & $-0.5-0.50$ \\
Temerloh & Moderate & 0.0506 & $-0.5-0.50$ \\
Raub & Moderate & 0.0259 & $-0.5-0.50$ \\
Lipis & Moderate & 0.0226 & $-0.5-0.50$ \\
Jerantut & Low & 0.0115 & $<-0.50$ \\
Bera & Low & 0.0245 & $<-0.50$ \\
Cameron & Low & 0.0155 & $<-0.50$ \\
Highlands & Low & & \\
\hline
\end{tabular}

\begin{tabular}{|lr|}
\hline Classification Statistics \\
\hline Count: \\
Minimum: & 11 \\
Maximum: & 0.012 \\
Sum: & 0.13 \\
Mean: & 0.40 \\
Median: & 0.036 \\
Standard Deviation: & 0.025 \\
\hline
\end{tabular}

Figure 8. Classification statistics information generated in GIS software

The qualitative thematic map derived from the combination of the social vulnerability index map and the seismic hazard map (Figure 9) is interpreted in order to identify spatial variability of exposure to seismic hazard in Pahang.

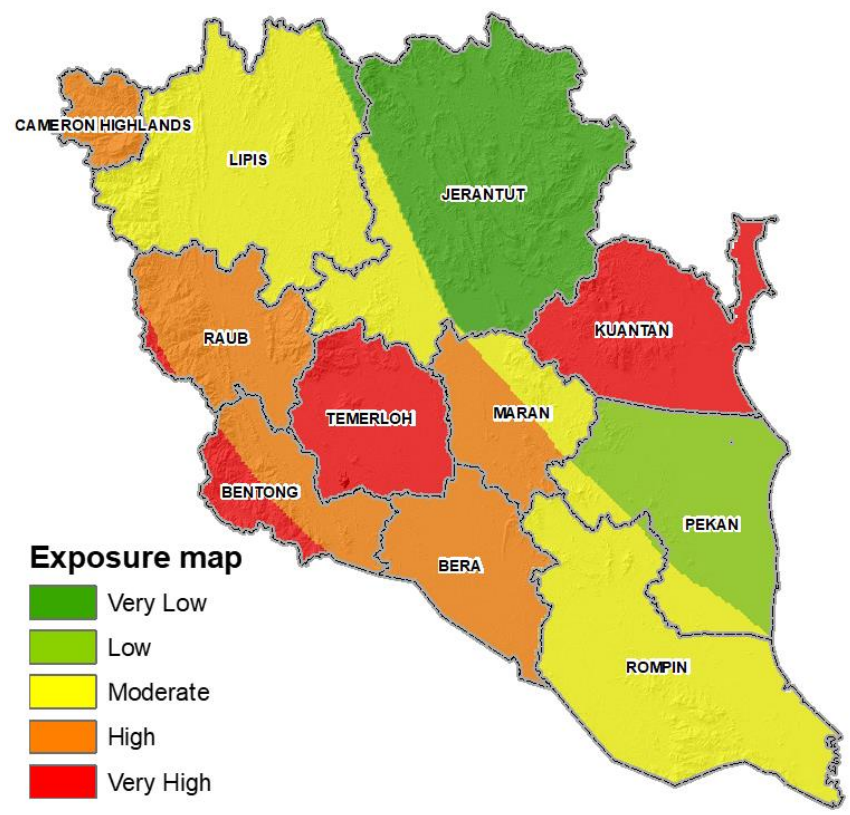

Figure 9. Social vulnerability exposure to seismic hazard

A composite representation of the social vulnerability variables and their exposition to seismic hazard events in a map is perhaps useful as an instrument for determining the geographical location of the most vulnerable area with greater accuracy. The output reveal that Bentong, Temerloh, Kuantan, and part of Raub districts are denoted in red, which is classified as highly exposed to earthquake disaster. Surprisingly, despite the low likelihood of earthquakes occurring in Kuantan, certain high-level social vulnerabilities have led the area to be classified as 'very high seismically vulnerable'. Similarly, the higher exposure of Temerloh is attributed to the larger number of residents living there, which includes children (age less than 15 years old), the elderly (more than 65 years old), women, the disabled; population density, and household density.

Major parts of Jerantut and Pekan that lies in Zone II are not at risk, which have both lower possibilities of an earthquake occurrence and lower exposure level attributed to the combination of social vulnerability indicators. Moderate and high exposure values are present on the remaining central part of the region, which refers to Cameron Highlands, Lipis, Raub, Rompin, Bera, parts of Jerantut, Maran and, Pekan. 


\section{CONCLUSION}

This research analyzed the social vulnerability to seismic hazard in Pahang by applying the multivariate data analysis and GIS technology at the district level. Firstly, a set of social indicators has been proposed in this study that is based on previous studies and readily available data in classifying and evaluating the local attributes that contribute to the degree of social vulnerability to disaster events. Based on the assessment, majority of the study region is relatively low to moderate level of social vulnerability index.

Secondly, the combination of the social vulnerability map and seismic hazard map through GIS map algebra process, produces the final exposure vulnerability map. The results of the study reveal that, districts in the central parts of the region are the most highly exposed to earthquake threats, whereas in the eastern part it demonstrates the low level of exposure to seismic hazard (with the exception for the Kuantan district, where it is highly vulnerable). The spatial variability of exposure vulnerability to Pahang's seismic hazard would enable policymakers to make appropriate decisions at the preliminary stage of disaster risk reduction and mitigation strategies.

This study is the first attempt in identifying the spatial distribution of vulnerability of Pahang's exposure to earthquake disasters, which involving the social factors. However, the use of the mentioned factors alone should be made with due care. Considering the resilience and the coping capacity factors that could contribute to earthquake risk, it would be most prudent if future study or research could be made in improving the accuracy of assessment results in some areas. In addition, the collection of social indicators and methodologies in this research could be extended and generalized to other regions by adjusting the appropriate variables and their respective weights.

\section{ACKNOWLEDGMENT}

The authors are especially grateful to government agencies (DOSM, JMG, and MacGDI) in providing main data for this research. The authors also acknowledged the constructive reviews of anonymous reviewers, which notably enriched the document.

\section{REFERENCES}

[1] UN-ISDR. (2017). Terminology on Disaster Risk Reduction. https://www.undrr.org/terminology, accessed on March 14, 2019.

[2] ADPC. (2003). Asian Disaster Preparedness Center: Third Regional Training Course on Earthquake Vulnerability Reduction for Cities. Dhaka, Bangladesh.

[3] Fritzsche, K., Schneiderbauer, S., Bubeck, P., Kienberger, S., Buth, M., Zebisch, M., Kahlenborn, W. (2014). The vulnerability sourcebook: Concept and guidelines for standardised vulnerability assessments. Deutsche Gesellschaft Für Internationale Zusammenarbeit - GIZ.

[4] Birkmann, J., Cardona, O.D., Carreño, M.L., Barbat, A.H., Pelling, M., Schneiderbauer, S., Welle, T. (2013). Framing vulnerability, risk and societal responses: The MOVE framework. Natural Hazards, 67(2): 193-211. http://dx.doi.org/10.1007/s11069-013-0558-5
[5] Cutter, S.L., Boruff, B.J., Shirley, W.L. (2003). Social vulnerability to environmental hazards. Social Science Quarterly, 84(2): 242-261. https://doi.org/10.1111/15406237.8402002

[6] Vicente, R., Parodi, S., Lagomarsino, S., Varum, H., Silva, J.A.R.M. (2011). Seismic vulnerability and risk assessment: Case study of the historic city centre of Coimbra. Portugal, 2011(9): 1067-1096. http://dx.doi.org/10.1007/s10518-010-9233-3

[7] Birkmann, J. (2007). Risk and vulnerability indicators at different scales: Applicability, usefulness and policy implications. Environmental Hazards, 7(1): 20-31. https://doi.org/10.1016/j.envhaz.2007.04.002

[8] Vinchon, C., Carreño, M.L., Contreras-Mojica, D.M., Kienberger, S., Schneiderbauer, S., Alexander, D., Welle, T. (2011). MOVE - Assessing vulnerability to natural hazards in Europe: From Principles to Practice A manual on concept. Methodology and Tools, (211590): 1-48.

[9] Carreño, M.L., Cardona, O.D., Barbat, A.H. (2007). Urban seismic risk evaluation: A holistic approach. Natural Hazards, 40(1): 137-172. https://doi.org/10.1007/s11069-006-0008-8

[10] Aksha, S.K., Juran, L., Resler, L.M., Zhang, Y. (2019). An analysis of social vulnerability to natural hazards in Nepal using a modified social vulnerability index. International Journal of Disaster Risk Science, 10(1): 103-116. https://doi.org/10.1007/s13753-018-0192-7

[11] Flanagan, B.E., Gregory, E.W., Hallisey, E.J., Heitgerd, J.L., Lewis, B. (2011). A social vulnerability index for disaster management. Journal of Homeland Security and Emergency Management, 8(1): 1-22. https://doi.org/10.2202/1547-7355.1792

[12] Morrow. (1999). Identifying and mapping community vulnerability. $\quad$ Disasters, 23(1): 1-18. https://doi.org/10.1111/1467-7717.00102

[13] Azzimonti, O.L., Colleoni, M., De Amicis, M., Frigerio, I. (2019). Combining hazard, social vulnerability and resilience to provide a proposal for seismic risk assessment. Journal of Risk Research, 1-17. https://doi.org/10.1080/13669877.2019.1646308

[14] de Loyola Hummell, B.M., Cutter, S.L., Emrich, C.T. (2016). Social vulnerability to natural hazards in Brazil. International Journal of Disaster Risk Science, 7(2): 111122. https://doi.org/10.1007/s13753-016-0090-9

[15] Martins, V.N., e Silva, D.S., Cabral, P. (2012). Social vulnerability assessment to seismic risk using multicriteria analysis: The case study of Vila Franca do Campo (São Miguel Island, Azores, Portugal). Natural Hazards, 62(2): 385-404. https://doi.org/10.1007/s11069-012-0084-x

[16] Adnan, A., Ramli, M.Z., Abd Razak, S.M. (2015). Disaster Management and Mitigation for Earthquakes: Are We Ready?. 9th Asia Pacific Structural Engineering and Construction Conference (APSEC2015), pp. 34-44.

[17] UNISDR. (2016). UNISDR Science and Technology Conference on the implementation of the Sendai Framework for Disaster Risk Reduction 2015- 2030: Exposure and Vulnerability.

[18] Marto, A., Tan, C.S., Kasim, F., Mohd.Yunus, N.Z. (2013). Seismic impact in Peninsular Malaysia. The 5th International Geotechnical Symposium - Incheon, pp. 22-24. https://doi.org/10.13140/2.1.3094.9129

[19] Shuib, M.K. (2009). The recent Bukit Tinggi earthquakes and their relationship to major geological structures. 
Bulletin of the Geological Society of Malaysia, 55: 6772.

[20] Tate, E. (2012). Social vulnerability indices: A comparative assessment using uncertainty and sensitivity analysis. Natural Hazards, 63(2): 325-347. https://doi.org/10.1007/s11069-012-0152-2

[21] Bahadori, H., Hasheminezhad, A., Karimi, A. (2017). Development of an integrated model for seismic vulnerability assessment of residential buildings: Application to Mahabad City, Iran. Journal of Building Engineering, $\quad 12$ : 118-131 https://doi.org/10.1016/j.jobe.2017.05.014

[22] Frigerio, I., Ventura, S., Strigaro, D., Mattavelli, M., De Amicis, M., Mugnano, S., Boffi, M. (2016). A GIS-based approach to identify the spatial variability of social vulnerability to seismic hazard in Italy. Applied Geography, 74: 12-22. https://doi.org/10.1016/j.apgeog.2016.06.014

[23] Ronoh, S., Gaillard, J.C., Marlowe, J. (2015). Children with disabilities and disaster risk reduction: A review. International Journal of Disaster Risk Science, 6(1): 3848. https://doi.org/10.1007/s13753-015-0042-9

[24] Cutter, S.L., Burton, C.G., Emrich, C.T. (2010). Disaster resilience indicators for benchmarking baseline conditions. Journal of Homeland Security and Emergency Management, 7(1): 1-22. https://doi.org/10.2202/1547-7355.1732

[25] Rafiq, L., Blaschke, T. (2012). Disaster risk and vulnerability in Pakistan at a district level. Geomatics, Natural Hazards and Risk, 3(4): 324-341. https://doi.org/10.1080/19475705.2011.626083

[26] Armaş, I., Toma-Danila, D., Ionescu, R., Gavriş, A. (2017). Vulnerability to earthquake hazard: Bucharest case study, Romania. International Journal of Disaster Risk $\quad$ Science, $8(2)$ : 182-195 https://doi.org/10.1007/s13753-017-0132-y

[27] USGS. (2018). What is seismic hazard? https://www.usgs.gov/natural-hazards/earthquakehazards/earthquakes, accessed on October 24, 2018.

[28] PLANMALAYSIA. (2018). Guidelines for Development Planning and Management in Earthquake Disaster Risk Areas.

[29] Papathoma-Köhle, M., Cristofari, G., Wenk, M., Fuchs, S. (2019). The importance of indicator weights for vulnerability indices and implications for decision making in disaster management. International Journal of Disaster Risk Reduction, 36: 101103. https://doi.org/10.1016/j.ijdrr.2019.101103

[30] Cardona, O.D., Carreño, M.L. (2013). Updating the indicators of disaster risk and risk management for the Americas. J. Integr. Disaster Risk Manag., 1(1): 27-47. https://doi.org/10.5595/idrim.2011.0014

[31] Jena, R., Pradhan, B., Beydoun, G. (2020). Earthquake vulnerability assessment in Northern Sumatra province by using a multi-criteria decision-making model. Int. J. Disaster Risk Reduct., 46: 101518. https://doi.org/10.1016/j.ijdrr.2020.101518

[32] Raduan, R., Daud, M.E., Kaamin, M. (2018). Applications GIS for earthquake threat mapping in Sabah. MATEC Web of Conferences, p. 07001. https://doi.org/10.1051/matecconf/201825007001

[33] Duong, H.H., Thuc, T., Ribbe, L. (2016). Assessing and Calculating a Climate Change Vulnerability Index for Agriculture Production in the Red River Delta, Vietnam. Redefining Diversity and Dynamics of Natural Resources Management in Asia (Vol. 2). Elsevier Inc., https://doi.org/10.1016/B978-0-12-805453-6.00003-6

[34] Iyengar, N., Sudarshan, P. (1982). A Method of classifiying regions from multivariate data. Economic and Political Weekly, 17(51), 2048-2052.

[35] UNDP. (2018). Technical Notes: Calculating the human development indices-graphical presentation. http://hdr.undp.org/sites/default/files/hdr2016 technical notes.pdf, accessed on October 24, 2018. 